\title{
The Difference of Dental Anxiety Levelon Healthcare and Non-Healthcare Students
}

\author{
Sarah Amelia ${ }^{1}$, Devi Listiani ${ }^{1}$, Az Andini F. ${ }^{1}$, Natalia Monique $\mathbf{J}^{\mathbf{1}}$, \\ Awalia Aprilizahrani P. ${ }^{1}$, Zakiya Rizki S. ${ }^{1}$, Retno Palupi ${ }^{2}$ \\ ${ }^{1}$ Undergraduate Student of Dental Medicine, Department Dental Public Health, Faculty of Dental Medicine, \\ Universitas Airlangga Indonesia, ${ }^{2}$ Staff Lecturer, Department of Dental Public Health, Faculty of Dental Medicine, \\ Universitas Airlangga Indonesia
}

\begin{abstract}
Backgrounnd: Dental anxiety can be a problem, both for dentists and patients. Basic Health Research states that as many as $57.6 \%$ of Indonesian people suffer from dental and mouth problems and only $10.2 \%$ of that number goes to the dentist, which can be caused by dental anxiety. Someone who has dental anxiety will avoid and refuse to check the condition of their teeth, which will adversely affect the health of the oral cavity.

Purposes: Examining the differences in levels of dental anxiety in healthcare and non-healthcare students at Universitas Airlangga.

Method: This study uses a quantitative type of cross-sectional method involving healthcare and nonhealthcare students and is carried out througout on campus A and campus B of Universitas Airlangga by random sampling. Data collection procedures were carried out through the Corah Dental Anxiety Scale (DAS) questionnaire with a few modifications that were disseminated online. Then the data analysis was performed using the chi square method to get results.

Result and Discussion: Based on research that has been done, healthcare students have a low percentage of dental anxiety levels of $64.6 \%$ where non-healthcare students have a high percentage of dental anxiety levels of $42.9 \%$. Different levels of dental anxiety may be influenced by different levels of knowledge about oral health and dental health.
\end{abstract}

Conclusion: There is a significant difference in the level of dental anxiety in healthcare and non-healthcare students at Universitas Airlangga.

Keywords: Dental anxiety, healthcare students, non-healthcare students.

\section{Introduction}

Dental anxiety can be a problem, both for dentists and patients. The term dental anxiety refers to the specific

\section{Corresponding Author: \\ Retno Palupi}

J1. Prof. Dr. Moestopo No. 47

Phone Numbers: (+6231) 5030255, 5020256

Facsimile Numbers: (+6231) 5020256

e-mail: pretno7774@gmail.com response given by a patient to a dentist's actions that can be associated with anxiety or fear ${ }^{1}$. The high incidence of dental anxiety in patients can lead to negative responses that can complicate dental health care measures so it is difficult to get optimal treatment results ${ }^{2,3}$.

If someone experiences dental anxiety, they will certainly avoid and refuse to check the condition of their teeth ${ }^{4,5}$. This can adversely affect the health of the oral cavity, such as tooth loss, dental caries and poor periodontal tissue conditions ${ }^{6}$. Based on the Basic Health Research in Indonesia on 2018, as many as 57.6\% of Indonesian people, especially adults and adolescents, 
suffer from dental and mouth problems, but only $10.2 \%$ of sufferers of the problem get treatment from dentists.

Anxiety and fear of a thing can arise when there is no or lack of knowledge and experience of a person to the thing. ${ }^{7}$ Among students, differences in the scope of studies will lead to different perceptions of a matter, one of which is about dental health ${ }^{8,9}$. Students with a scope of study in the field of health will have a different perception than students in the scope of non-health studies of dental health which will make a difference in the level of dental anxiety ${ }^{10,11}$. Therefore, the authors would like to see differences in the level of dental anxiety among healthcare and non-healthcare students ${ }^{12-14}$.

This study has a general objective to determine differences in the level of dental anxiety in healthcare and non-healthcare students at Universitas Airlangga, with the specific purpose of analyzing the differences in levels of dental anxiety in healthcare and non-healthcare students at Universitas Airlangga. The author hopes that with this research, for educational institutions, it can be a scientific contribution in learning about dental anxiety and for students, it can be a means of adding insight, especially in the case of dental anxiety.

\section{Research Method}

This research is a type of quantitative research with a cross-sectional design, which is data retrieval in a certain period of time. Data collection from samples is done at the same time. The use of cross-sectional study is carried out in the same period, not in the past or future from the formulation of the existing problem. This type of research is more practical to examine the quantity of different levels of anxiety and fear in healthcare and non-healthcare students at Universitas Airlangga.

This research was conducted throughout Campus A of Universitas Airlanggaand Campus B of Universitas Airlangga, because this study involve a sample of healthcare and non-healthcare students at Universitas Airlangga. The research targets that must be achieved at least are at least 50 campus A students at Universitas Airlanggaand 50 campus B students at Universitas Airlanggaas research samples.

In this study, questionnaires with closed questions were used as research instruments. Questionnaire with closed questions is a questionnaire that gives options or options to respondents to choose the answers available in the questionnaire. The questionnaire in this study consisted of 5 questions and will be distributed online to respondents.

Data taken from questionnaire related to dental anxiety. The questionnaire we used in this study was a modified version of the Corah Dental Anxiety Scale (DAS), which contained several additional questions to refer to the respondents' feelings about local anesthetic injections with a main reference to the injection site, because the pain experienced with local anesthetic injections varied. according to its location in the mouth. In addition, the simplified 5-point scale answering scheme is designed from not worried to very worried. The modified dental anxiety scale (MDAS) contains 5 multiple choice items including the following:

- If you go to the dentist for treatment tomorrow, how do you feel?

- If you sit in the dentist practice waiting room, how do you feel?

- If you find that your teeth will be drilled, how do you feel?

- If you do scaling and polishing on your teeth, how do you feel?

- If you are going to get an injection of local anesthetic in your gum, how do you feel?

Scores for each of the 5 response items are summarized to provide estimated values of dental anxiety. Other data that we will include in the questionnaire that will be given to the sample are Gender, Year Class, Faculty and Study Program.

The data was taken using an online questionnaire in the form of a google containing sample data source questions that will be distributed to students of the faculty of healthcare and non-healthcare faculty students of Universitas Airlangga.

Data was collected by distributing online questionnaires containing sample data source questions through social media or distributing messages through groups containing students from the healthcare and non-healthcare faculties of Universitas Airlangga. The study was conducted by random sampling of the study population. Data collection is done every day for one week until the data sample is met or more than the target depending on the time specified for one week. If within one week the sample does not match the target data, 
the data collection will continue until $\mathrm{H}+3$ from the predetermined timeline.

Data collected will be analysed using the Chi Square method. Chi Square is one type of non-parametric comparative test conducted on two variables, where the scale of the data for both variables is nominal.

The basic principle of the chi square test is to compare the frequency that occurs (observation) with the frequency of expectations (expectations). If the observed frequency values are the same with the expected frequency values, then there is no meaningful (significant) difference and vice versa, if the value of the observation frequency and the expectation frequency value are different, then there is a meaningful (significant) difference.

\section{Result}

Table 1 Results of Differences in Dental Anxiety Levels in Healthcare and Non-Healthcare Students of Universitas Airlangga using the Chi Square method

\begin{tabular}{|l|c|c|c|c|c|c|}
\hline \multirow{2}{*}{ Students Major } & \multicolumn{2}{|c|}{ Level of Dental Anxiety } & \multirow{2}{*}{ Total (\%) } & P-value & $\begin{array}{c}\text { Contingency } \\
\text { Coefficient }\end{array}$ & $\begin{array}{c}\text { Prevalence } \\
\text { Ratio }\end{array}$ \\
\cline { 2 - 4 } & High (\%) & Low (\%) & & & \\
\hline Healthcare & $23(35,4 \%)$ & $42(64,6 \%)$ & $65(57 \%)$ & & \multirow{2}{*}{0.032} & 0.032 \\
\hline Non-Healthcare & $28(57,1 \%)$ & $21(42,9 \%)$ & $49(43 \%)$ & & \\
\hline Total & 51 & 63 & & & \\
\hline
\end{tabular}

Based on table 1, the results showed that of 65 healthcare student correspondents, 42 of them had low levels of dental anxiety and 23 other students had high levels of dental anxiety. Whereas in the 49 non-healthcare student correspondents, there were 21 students who had low levels of dental anxiety and 28 other students had high levels of dental anxiety. Based on table 1, the significance value is 0.032 . While the alpha standard value is 0.05 . Significance values that were more than the alpha standard did not show significant differences, whereas significance values that were less than the alpha standard showed significant differences. So the results in table 1 can be said to be significant.

Table 2. Comparison of the Number of Healthcare and Non-Healthcare Students Feeling Fear of a Dental Action Condition

\begin{tabular}{|l|c|c|c|}
\hline \multirow{2}{*}{ Condition } & \multicolumn{2}{|c|}{ Students Major } & \multirow{2}{*}{ P-value } \\
\cline { 2 - 3 } & Healthcare (\%) & Non-Healthcare (\%) & 0,0156 \\
\hline Doing a checkup to the dentist & $1(1,5 \%)$ & $0(0 \%)$ & 0,021 \\
\hline Waiting in dentist waiting room & $1(1,5 \%)$ & $0(0 \%)$ & 0,042 \\
\hline Drilling will be performed on the teeth & $5(7,7 \%)$ & $9(18,4 \%$ & 0,046 \\
\hline Scaling and cleaning will be done & $1(1,5 \%)$ & $2(4,1 \%)$ & 0,626 \\
\hline Getting injection (local anesthesia) on the gum & $14(21,5 \%)$ & $11(22,4 \%)$ & \multirow{2}{*}{0} \\
\hline
\end{tabular}

Based on table 2, the results are obtained that of 65 healthcare student correspondents, 1 of them felt afraid when going to visit the dentist, while waiting in the waiting room of the dentist's clinic, as well as when it would be done to scaling and polishing. While of the 49 non-healthcare student correspondents, there were no students who felt afraid when they were going to visit the dentist and while waiting in the waiting room of the 
dentist clinic, but there were 1 students who felt afraid of the act of scaling and polishing. In the drilling action, there were 5 healthcare students who felt afraid, while in non-healthcare students there were 9 students who felt afraid of the action. Fear most felt by students on the condition of care that requires the provision of local anesthesia on the gums, found 14 healthcare students and 11 non-healthcare students who are afraid of these actions.

\section{Discussion}

Based on the results of the study in table 1 related to differences in the level of dental anxiety in healthcare and non-healthcare faculty students at Universitas Airlangga shows that the healthcare faculty students have a low dental anxiety level of $64.6 \%$, whereas in students from non-healthcare faculties have a low dental anxiety level of $42.9 \%$. These percentages illustrate that healthcare faculty students in general have lower levels of dental anxiety when compared to students from non-healthcare faculties. These different levels of dental anxiety can be influenced by differences in the level of knowledge about oral health and dental health ${ }^{15}$. Healthcare students are considered to have higher knowledge and awareness compared to nonhealthcare students, so many healthcare students are more likely to take care of their health and one of them is dental and oral health ${ }^{16,17}$. The main reason is because basically, healthcare students are already equipped with knowledge about dental and oral health, both basic and specific. With this knowledge that is considered good, there will be a sense of familiarity with the care actions that will be taken when patients come to visit the dentist. Whereas for non-healthcare students with lower levels of knowledge and information, there is no familiarity and there is no description of the treatment actions that will be taken when patients come to the dentist so that it will cause anxiety to fear ${ }^{18,19}$.

Based on table 2 related to the results of a survey regarding fear of a certain dental care condition, the highest results were obtained for injections (local anesthesia) in the gums, which was $21.5 \%$ in healthcare students and $22.4 \%$ in non-healthcare students. This indicates that in general, patients feel anxious or afraid when they will get anesthesia. Fear of using anesthesia can be caused by the patient having never received anesthesia before, anxiety if the anesthesia process does not take place smoothly, fear if awakened/awakened during operative measures and anxiety about some of the side effects of the anesthetic drug itself $f^{3,20,21}$.
The importance of proper diagnosis of dental anxiety cannot be underestimated. Identifying anxious patients helps dental health practitioners in planning treatment actions with appropriate procedures for patients. Some method that can be performed by dental health practitioners to deal with patients with dental anxiety is to do a communication approach to patients before treatment ${ }^{15,22}$.

High levels of dental anxiety can be minimized by means of education about oral health and teeth, regular visits to the dentist at least every 6 months and from the communication and good relationships with patients ${ }^{23}$.

\section{Conclusion}

There is a significant difference in the level of dental anxiety in healthcare and non-healthcare students at Universitas Airlangga.

Conflict of Interest: There are no conflicts of interest.

Source of Funding: Self-Funding

Ethical Clearance: Approved

\section{References}

1. Halvari A, Halvari H, Deci E. Dental anxiety, oral health-related quality of life and general wellbeing: A self-determination theory perspective. J Appl Soc Psychol. 2019;49(5):295-306.

2. Al-Omari W, Al-Omiri M. Dental anxiety among university students and its correlation with their field of study. J Appl Oral Sci. 2009;17(3):199203.

3. Yakar B, Kaygusuz T, Pırınçcı E. Evaluation of Dental Anxiety and Fear in Patients who Admitted to the Faculty of Dentistry: Which Patients are More Risky in terms of Dental Anxiety. Ethiop J Heal Sci. 2019;29(6719-26).

4. Widyagarini A, Suharsini M. Dental care for children with autism spectrum disorder. Dent J (Majalah Kedokt Gigi). 2018;50(3):160.

5. Susilawati S, Monica G, Fadilah RPN, Bramantoro $\mathrm{T}$, Setijanto D, Wening GRS, et al. Building team agreement on large population surveys through inter-rater reliability among oral health survey examiners. Dent J (Majalah Kedokt Gigi). 2018;51(1):42-6.

6. Appukuttan D. Strategies to manage patients with 
dental anxiety and dental phobia: Literature review. Clin Cosmet Investig Dent. 2016;8:35-50.

7. Astuti LA, Nurnaeni, Umar F, Tahir H, Amin A. Anxiety level of dental care among adolescents in Kepulauan Selayar District. Indian J Public Heal Res Dev [Internet]. 2019;10(1):409-12.

8. Pratiwi R, Akbar FH, Muhiddin NH. Relationship between stress level, fatigue symptoms and sleep quality with oral health behavior among preclinical student faculty of pharmacy, Indonesia. Pesqui Bras Odontopediatria Clin Integr [Internet]. 2018;18(1).

9. Setijanto RD, Bramantoro T, Palupi R, Hanani A. The role of attitude, subjective norm and perceived behavioral control (PBC) of mothers on teaching toothbrushing to preschool children - Based on the Theory of Planned Behavior: A cross-sectional study. Fam Med Prim Care Rev. 2019;21(1):53-7.

10. Ozlek E, Yıldırım A, Koc A, Boysan M. Sociodemographic determinants of dental anxiety and fear among college students. . East J Med. 2019;24(2):169-75.

11. Gunjal S, Pateel D, Parkar S. Dental Anxiety among Medical and Paramedical Undergraduate Students of Malaysia. Int J Dent. 2017;2017.

12. Pardede AMH, Mawengkang H, Zarlis M, Tulus T. Optimization of health care services with limited resources. Int J Adv Sci Eng Inf Technol. 2019;9(4):1444-9.

13. Siahaan L, Alrasyid H, Akbari R, Eyanoer P, Panggabean M, Panggabean Y. Rapid diagnostic tests to detect asymptomatic malaria in primary health care facilities in hypoendemic areas. Fam Med Prim Care Rev. 2016;18(4):470-2.

14. Lendrawati L, Pintauli S, Rahardjo A, Bachtiar A, Maharani DA. Risk factors of dental caries: Consumption of sugary snacks among indonesian adolescents. Pesqui Bras Odontopediatria Clin Integr. 2019;19(1):1-8.
15. Yildirim T, Dundar S, Bozoglan A, Karaman T, Dildes N, Kaya F, et al. Is there a relation between dental anxiety, fear and general psychological status? PeerJ. 2017;2(1-11.).

16. Storjord H, Teodorsen M, Bergdahl J, Wynn R, Johnsen J. Dental anxiety: A comparison of students of dentistry, Biology, And psychology. J Multidiscip Heal. 2014;7:413-8.

17. Sghaireen M, Zwiri A, Alzoubi I, Qodceih S, AlOmiri M. Anxiety due to dental treatment and procedures among university students and its correlation with their gender and field of study. Int J Dent. 2013;2013.

18. Dou L, Vanschaayk M, Zhang Y, Fu X, Ji P, Yang D. The prevalence of dental anxiety and its association with pain and other variables among adult patients with irreversible pulpitis. BMC Oral Heal. 2018;18(1):1-6.

19. Ali S, Farooq I, Khan S, Moheet I, Al-Jandan B, Al-Khalifa K. Self-reported anxiety of dental procedures among dental students and its relation to gender and level of education. J Taibah Univ Med Sci. 2015;10(4):449-53.

20. Ruhaiyem M, Alshehri A, Saade M, Shoabi T, Zahoor H, Tawfeeq N. Fear of going under general anesthesia: A cross-sectional study. Saudi J Anaesth. 2016;10(3):317-21.

21. Iqbal M. Anxiety Related To Dental Procedures. Isra Med J. 2011;38(1):22-3.

22. White A, Giblin L, Boyd L. The Prevalence of Dental Anxiety in Dental Practice Settings. J Dent Hyg JDH. 2017;91(1):30-4.

23. Crego A, Carrillo-Díaz M, Armfield J, Romero M. From public mental health to community oral health: The impact of dental anxiety and fear on dental status. Front Public Heal. 2014;2:14-7. 